\title{
Not just numbers: beyond counting caesarean deliveries to understanding their determinants in Ghana using a population based cross-sectional study
}

Abdul-Aziz Seidu ${ }^{1 *}$ (D), John Elvis Hagan Jr. ${ }^{2,3}$ (D), Wonder Agbemavi ${ }^{1}$ (D), Bright Opoku Ahinkorah ${ }^{4}$ (D) Edmond Banafo Nartey ${ }^{5}$, Eugene Budu ${ }^{1}$ (D) Francis Sambah² ${ }^{2}$ and Thomas Schack ${ }^{3}$

\begin{abstract}
Background: The increasing rate of caesarean deliveries (CD) has become a serious concern for public health experts globally. Despite this health concern, research on factors associated CD in many low- and -middle countries like Ghana is sparse. This study, therefore, assessed the prevalence and determinants of CD among child-bearing women aged 15-49 in Ghana.

Methods: The study used data from the 2014 Ghana Demographic and Health Survey. The analysis was limited to mothers $(n=2742)$ aged $15-49$, who had given birth in health facilities 5 years preceding the survey. Association between CD and its determinants was assessed by calculating adjusted odds ratios (AOR) with their respective 95\% confidence intervals using a binary logistic regression.

Results: The percentage of mothers who delivered their babies through caesarean section (CS) was $18.5 \%$. Using multivariable logistic regression, the results showed that women aged $45-49$ ( $A O R=10.5 ; 95 \% \mathrm{Cl}$ : 3.0-37.4), and women from a household that are headed by a female $(A O R=1.3 ; 95 \% \mathrm{Cl}=1.1-1.7)$ had higher odds to deliver through CS. Women from the Upper East (AOR $=0.4 ; 95 \% \mathrm{Cl}=0.2-0.7$ ) and Upper West (AOR $=0.4 ; 95 \% \mathrm{Cl}=0.2-0.8$ ) regions had lower odds to deliver their children through $\mathrm{CS}$. Women with parity 4 or more $(A O R=0.3 ; 95 \% \mathrm{Cl}=$ $0.2-0.5$ ) had lower odds of CD compared to those with parity 1 . Women with female babies had lower odds $(A O R=0.8 ; C l=0.7-0.9)$ of delivering them through CS compared to those with male children.

Conclusion: The percentage of women delivering babies through the CS in Ghana is high. The high rates of CD noted do not essentially indicate good quality care or services. Hence, health facilities offering this medical protocol need to adopt comprehensive and strict measures to ensure detailed medical justifications by doctors for performing these caesarean surgeries.
\end{abstract}

Keywords: Caesarean, Delivery, Ghana, Women, Obstetric

\footnotetext{
* Correspondence: abdul-aziz.seidu@stu.ucc.edu.gh

'Department of Population and Health, University of Cape Coast, Cape Coast,

Ghana

Full list of author information is available at the end of the article
}

(c) The Author(s). 2020 Open Access This article is distributed under the terms of the Creative Commons Attribution 4.0 International License (http://creativecommons.org/licenses/by/4.0/), which permits unrestricted use, distribution, and reproduction in any medium, provided you give appropriate credit to the original author(s) and the source, provide a link to the Creative Commons license, and indicate if changes were made. The Creative Commons Public Domain Dedication waiver (http://creativecommons.org/publicdomain/zero/1.0/) applies to the data made available in this article, unless otherwise stated. 


\section{Background}

Caesarean Section (CS) is one of the obstetric interventions introduced to help decrease maternal and foetal mortality and morbidity [1]. This medical protocol is a surgical procedure in which an incision is made through a mother's abdomen and uterus to deliver one or more babies, or rarely, to remove a dead foetus [2]. This surgical procedure is viewed as one of the major World Health Organization's (WHO) medically suggested plan towards improving availability, accessibility, quality, and the use of services for the management and treatment of complications of pregnancy, labour, and delivery [3]. CS is also considered an essential treatment for antepartum haemorrhage, prolonged or obstructed labour, preeclampsia or eclampsia, and intrapartum foetal distress [4]. Nevertheless, a 2008 WHO survey of 373 facilities across 24 countries found that caesareans deliveries (CD) were associated with an increased risk of maternal mortality and serious outcomes for mothers and newborn infants, compared with spontaneous vaginal delivery (VD) [5]. There are 6 to 10 times more complications among women having a CD than a VD, with emergency CDs being two to four times riskier than elective [6].

WHO review from Northern European countries suggests that good maternal and perinatal outcomes are associated with the rate of CS [7]. The WHO concluded that there is no justifiable reason to support caesarean birth rates higher than $15 \%$ in any country. A rate between 5 and $15 \%$ of births undergoing a CS is optimal and has medical indications for $\mathrm{CD}$ [8], and rates above this are unsuitable and unnecessary, imposing financial burden and clinical risks on patients and healthcare systems [9]. A CD rate of less than 5\% also indicates the unmet need for skilled delivery service [10].

CS have in recent times been performed upon request for childbirths that could otherwise have been delivered vaginally and these have become a matter of serious concern for public health experts globally [2]. The WHO reports that between 1990 and 2014, the global average CD rate increased from 12.4 to $18.6 \%$, with rates ranging between $6 \%$ in low- and -middle-income countries and $27.2 \%$ in high income countries [3] and rising at an average rate of $4.4 \%$ per year [4]. However, Africa recorded the lowest rate of $7.3 \%$, followed by Asia with 19.2\%, Europe recording 25\%, and the highest rates of 40.5\% from Latin America and the Caribbean [4].

In countries with high prevalence of $C D$, the factors that contribute to the high rates are low priority of enhancing women's own abilities to give birth, side effects of common labour interventions, refusal to offer the informed choice of vaginal birth, casual attitudes about surgery and variation in professional practice style, limited awareness of harm more likely with $\mathrm{CD}$, and incentives to practice in a manner that is efficient for providers
$[1,4]$. Other factors such as type of health facility-public or private [1], age $[1,11,12]$, birth order [13-15], birth weight $[11]$, place of residence $[1,16]$, region of residence [1], socioeconomic status, maternal educational level [1, 17], maternal request [18] and wealth status [1, 17] have all been found to be associated with CS. Most low- and -middle-income countriess (LMICS), however, report CD rates well below the acceptable minimum standard of $5 \%$ outlined by the WHO. For many LMICs (e.g., Niger, Ethiopia and Madagascar), the caesarean procedure is scarcely performed, hence the rates of births by $\mathrm{CD}$ are around $1.0 \%$ [19]. It has been established that in most LMICs, factors including inaccessibility to healthcare, weak healthcare system, inadequate health infrastructure, geographical barriers, cultural factors, poverty, and inadequate human resources are major impediments to providing CD to women who are in dire need of it [20].

Although there have been some studies on CD in Ghana, some of them focused on socioeconomic and demographic factors associated with $C D$ in southern Ghana [14], preference of Ghanaian women for vaginal or CD postpartum [21], validating women's self-report of emergency CD [18], vaginal birth after a previous CS [22] and clinical indications and feto-maternal outcomes and predictors of CD in Northern Ghana [23]. As far as we know, none of these studies have used a nationally representative sample to assess prevalence and the factors associated with $\mathrm{CD}$ among childbearing women in Ghana despite the country recording an overall rate of $16 \%$ [24], above the threshold given by WHO. The health system is structured with most of the deliveries initiated in health facilities that do not have the capacity to perform CS and lack ambulances for referrals of clients who need CS in Ghana [25]. Consequently, a lot of pregnant women who undergo emergency CS at referral hospitals have adverse obstetric outcomes as compared to clients who have been booked for parturient [25]. The central focus of this study was, therefore, to determine the prevalence and assess the factors associated with CD among childbearing women in Ghana.

\section{Methods}

\section{Study setting}

The study was carried out in the Republic of Ghana which is located on the West African Coast and has a total land area of $238,533 \mathrm{~km}^{2}$ with 16 administrative regions. Ghana is bordered by three francophone countries; Burkina Faso, Togo and Cote d'Ivoire. These countries lie on the north, East and West of Ghana respectively [24]. In Ghana, from the 2010 population and housing census, there are about 8 main ethnic groups. These are: Akan (47.5\%), Mole-Dagbani (16.6\%), Ewe (13.9\%), Ga-Dangme (7.4\%), Gurma (5.7\%), Guan (3.7\%), Grusi (2.5\%), Mande (1.1\%), and others (1.4\%, 
[26]. Again, the 2010 census report stated that $51 \%$ of the population in Ghana are found in urban areas whereas $49 \%$ are in rural areas. There are about 3217 functional health facilities, out of which 4 are teaching hospitals. Additionally, there are 9 regional hospitals, 3 psychiatric hospitals, 11 polyclinics, 59 Christian Health Association of Ghana (CHAG) hospitals, 10 Islamic hospitals, 96 government hospitals, 156 private hospitals, and 22 quasi-government hospitals, 389 maternity homes, and 379 Community-based Head Planning and Services (CHPS) compounds, with majority of these health facilities found in the urban areas $[26,27]$.

\section{Data source}

The data used for this study were obtained from the 2014 version of the Ghana Demographic and Health Survey (GDHS). The survey uses a standard DHS model questionnaire developed by the Measure DHS programme [24]. The GDHS is a nationwide survey which covers all the then 10 regions of Ghana. The survey is carried out by the GSS and Ghana Health Service with support from ICF International. The key focus of the survey is on child and maternal health in order to provide adequate data to help tract major population and health determinants in Ghana. Specifically, it collects data on fertility, contraceptive use, child health, nutrition, malaria, HIV and AIDS, family planning, health insurance and maternal health; antenatal care, delivery care and post-natal care [24]. For the purpose of this study, women who have given birth in health facilities 5 years preceding the survey were used, thus, 2742 women. Detailed decription of the sampling procedure has been provided in the survey report [24]. Permission to use the data set was given by the MEASURE DHS following the assessment of a proposal. Data set is available to the public at www.measuredhs.org.

\section{Description and definition of variables Dependent variable}

The study used $\mathrm{CD}$ as the dependent variable. It was derived from the response to the question "was (NAME) delivered by caesarean, that is, did they cut your belly open to take the baby out?" Responses were categorised Yes $=1$ or $\mathrm{No}=0$.

\section{Independent variables}

Fourteen independent variables were selected but not chosen arbitrary. The selection was guided by the varied conclusions drawn from some previous studies $[1,11$, $12,14,28,29]$ to be having an association with $\mathrm{CD}$. The independent variables that were used in this study were; maternal age, marital status, education, occupation, wealth status, residence, region, religion, ethnicity, parity (Birth order), number of ANC visits, sex of the baby, size of the baby, and household head's sex. Maternal age was captured in the DHS as "15-19", "20 - 24", " $25-29$ ", " 20 34", "35 - 39", "40 - 44", "45-49”. Marital status was recoded as "Single" and "Living together". We recoded educational level as "No education", "Primary education", "Secondary education" and "Higher education". Type of Residence was captured as "Urban" or "Rural". The then 10 regions were also captured in the survey as "Western", "Central", "Greater Accra", "Volta", "Eastern", "Ashanti", "Brong-Ahafo", "Northern", "Upper East", and "Upper West". Wealth index was measured in quintiles ("poorest", "poorer", "middle", "richer", "richest"). Ethnicity was coded as "Akan", "Ga/Adangbe", "Ewe", "Guan", "Mole-Dagbani", "Grussi", "Gruma", "Mande" and "Other". Parity was recoded as "1", " 2 ", "3" and " $4+$ " taking into consideration Ghana's current total fertility rate of 4.2 [24]. The sex of the baby was coded as "male" and "female". With respect to occupation, someone was considered as not working if the person was not engaging in any income generating venture; primary occupation was considered as an occupation focusing on the extraction of raw materials including all forms of agriculture; secondary occupation referred to the production industry which adds value to raw materials extracted through primary occupation whilst tertiary occupation involved provision of services. Size of a child at birth was originally coded as "very large", "larger than average", "Average", "smaller than average" and "very small". These were recoded as "Large" "Average" and "Small". Considering the recommendations of the WHO [7] and previous studies, a woman should have at least four antenatal visits to prevent negative health outcomes. ANC was therefore coded as " 0 ", " $1-3$ " and " 4 or more". The place of delivery was recoded as "private" or "public sector". Women who had home deliveries were not part of the inclusion criteria due to the fact that $C D$ cannot be performed at home [1]. In the Ghanaian context, the public sector includes government hospitals and rural health centres while the private sector includes private hospitals and clinics [30].

\section{Data analytical strategy}

STATA 14.1 for Mac OS (College Station, TX) Statistical Analytic tool was used for the analysis. The outcome variable, $\mathrm{CD}$ was coded $0=$ "No", and $1=$ "Yes." Both descriptive and inferential statistics were employed for data analyses. First, a descriptive analysis of socio-demographic characteristics of the participants was carried out and presented as frequencies and percentages in Table 1. Next, a pie chart was used to present results on the prevalence of CD using frequencies and percentages. Third, the association between the independent variables and the outcome variable were presented using a 2 by 2 contingency table and the results presented using chi-square $\left(x^{2}\right)$ 
Table 1 Socio-demographic characteristics of women aged 1549 years who gave birth in a health facility in Ghana

\begin{tabular}{lll}
\hline Variables & Weighted $n=2742$ & Weighted \% \\
\hline Age & & \\
$15-19$ & 61 & 2.2 \\
$20-24$ & 382 & 14.0 \\
$25-29$ & 697 & 25.4 \\
$30-34$ & 688 & 25.1 \\
$35-39$ & 586 & 21.4 \\
$40-44$ & 258 & 9.4 \\
$45-49$ & 69 & 2.5
\end{tabular}

Marital status

Single 209

Married 1899

Cohabitating 633

Education

No education $\quad 407$

Primary 255

Secondary $\quad 1726$

Higher

Occupation

Not working

Primary

Secondary

Tertiary

Wealth index

$\begin{array}{ll}\text { Poorest } & 388 \\ \text { Poorer } & 438 \\ \text { Middle } & 527 \\ \text { Richer } & 683 \\ \text { Richest } & 706 \\ \text { Residence } & \\ \text { Rural } & 1209 \\ \text { Urban } & 1543 \\ \text { Region } & \end{array}$

Western 276

Central 292

Greater Accra $\quad 560$

Volta 189

Eastern 231

Ashanti 554

Brong-Ahafo 250

Northern $\quad 178$

Upper East 141

Upper West

Religion
Table 1 Socio-demographic characteristics of women aged 1549 years who gave birth in a health facility in Ghana (Continued)

\begin{tabular}{lll}
\hline Variables & Weighted $n=2742$ & Weighted \% \\
\hline Christian & 2188 & 79.8 \\
Islam & 463 & 16.9 \\
Traditional/spiritual & 25 & 0.9 \\
No religion & 65 & 2.4
\end{tabular}

Ethnicity

$\begin{array}{lll}\text { Akan } & 1382 & 50.4 \\ \text { Ga/dangme } & 189 & 6.9 \\ \text { Ewe } & 369 & 13.5 \\ \text { Guan } & 54 & 2.0 \\ \text { Mole-dagbani } & 472 & 17.2 \\ \text { Grusi } & 86 & 3.1 \\ \text { Gurma } & 96 & 3.5 \\ \text { Mande } & 43 & 1.6 \\ \text { Other } & 51 & 1.9 \\ \text { Parity } & & \\ 1 & 567 & 20.7 \\ 2 & 605 & 22.1 \\ 3 & 542 & 19.8 \\ 4+ & 1028 & 37.5\end{array}$

ANC attendance

$\begin{array}{lll}0 & 15 & 0.5 \\ 1-3 & 143 & 5.2 \\ 4+ & 2584 & 94.3\end{array}$

Type of delivery facility

$\begin{array}{lll}\text { Public facility } \quad 2425 & 88.4\end{array}$

$\begin{array}{lll}\text { Private facility } & 317 & 116\end{array}$

Sex of baby

$\begin{array}{lll}\text { Male } & 1424 & 51.9 \\ \text { Female } & 1318 & 48.1\end{array}$

Baby size

$\begin{array}{lll}\text { Large } & 1417 & 51.7 \\ \text { Average } & 910 & 33.2 \\ \text { Small } & 415 & 15.2\end{array}$

Household head sex

\begin{tabular}{lll} 
Male & 2093 & 76.3 \\
Female & 649 & 23.7 \\
\hline
\end{tabular}

Source: Computed from 2014 GDHS

and $p$ values (see Table 2). The independent variables that were significant at $p<0.05$ at the bivariate level were used for the multivariable analysis. The results are presented in Table 3 with summary statistics at 95\% confidence intervals (CI). Since the outcome variable was a dichotomous variable, the binary logistic regression model was employed. All frequency distributions were 
Table 2 Bivariate analysis on delivery by caesarean among women aged 15-49 years who gave birth in a health facility in Ghana

\begin{tabular}{|c|c|c|c|c|}
\hline \multirow[t]{2}{*}{ Variables } & \multicolumn{2}{|c|}{ Delivery by caesarean section } & \multicolumn{2}{|c|}{ Chi-square } \\
\hline & No & Yes & $x^{2}$ & $p$-value \\
\hline Age & & & 37.5 & $0.000^{* * *}$ \\
\hline $15-19$ & 93.7 & 6.3 & & \\
\hline $20-24$ & 91.5 & 8.5 & & \\
\hline $25-29$ & 83.9 & 16.1 & & \\
\hline $30-34$ & 85.6 & 14.4 & & \\
\hline $35-39$ & 78.7 & 21.3 & & \\
\hline $40-44$ & 81.9 & 18.1 & & \\
\hline $45-49$ & 78.7 & 21.3 & & \\
\hline Marital status & & & 4.26 & 0.119 \\
\hline Never married & 82.4 & 17.6 & & \\
\hline Married & 83.7 & 16.3 & & \\
\hline Cohabitation & 87.0 & 13.0 & & \\
\hline Education & & & 50.4 & $0.000^{* * *}$ \\
\hline No education & 90.3 & 9.7 & & \\
\hline Primary & 90.7 & 9.3 & & \\
\hline Secondary & 82.5 & 17.5 & & \\
\hline Higher & 75.3 & 24.7 & & \\
\hline Occupation & & & 23.6 & $0.000^{* * *}$ \\
\hline Not working & 85.9 & 14.1 & & \\
\hline Primary & 89.6 & 10.4 & & \\
\hline Secondary & 82.8 & 17.2 & & \\
\hline Tertiary & 81.4 & 18.6 & & \\
\hline Wealth index & & & 95.2 & $0.000^{* * *}$ \\
\hline Poorest & 91.3 & 8.7 & & \\
\hline Poorer & 88.9 & 11.1 & & \\
\hline Middle & 85.9 & 14.1 & & \\
\hline Richer & 82.1 & 17.9 & & \\
\hline Richest & 71.5 & 28.5 & & \\
\hline Residence & & & 31.4 & $0.000^{* * *}$ \\
\hline Rural & 88.3 & 11.7 & & \\
\hline Urban & 80.5 & 19.5 & & \\
\hline Region & & & 65.2 & $0.000^{* * *}$ \\
\hline Western & 81.0 & 19.0 & & \\
\hline Central & 80.7 & 19.3 & & \\
\hline Greater accra & 74.9 & 25.1 & & \\
\hline Volta & 87.4 & 12.6 & & \\
\hline Eastern & 83.8 & 16.2 & & \\
\hline Ashanti & 77.5 & 22.5 & & \\
\hline Brong Ahafo & 86.6 & 13.4 & & \\
\hline Northern & 89.2 & 10.8 & & \\
\hline Upper East & 91.9 & 8.1 & & \\
\hline Upper West & 91.1 & 8.9 & & \\
\hline
\end{tabular}

Table 2 Bivariate analysis on delivery by caesarean among women aged 15-49years who gave birth in a health facility in Ghana (Continued)

\begin{tabular}{|c|c|c|c|c|}
\hline \multirow[t]{2}{*}{ Variables } & \multicolumn{2}{|c|}{ Delivery by caesarean section } & \multicolumn{2}{|c|}{ Chi-square } \\
\hline & $\overline{\mathrm{No}}$ & Yes & $x^{2}$ & $p$-value \\
\hline Religion & & & 3.0 & 0.393 \\
\hline Christian & 83.7 & 16.3 & & \\
\hline Islam & 86.5 & 13.5 & & \\
\hline Traditional/spiritual & 86.1 & 13.9 & & \\
\hline No religion & 82.5 & 17.5 & & \\
\hline Ethnicity & & & 32.1 & $0.000^{* * *}$ \\
\hline Akan & 80.3 & 19.7 & & \\
\hline Ga/Adangme & 79.9 & 20.1 & & \\
\hline Ewe & 85.5 & 14.5 & & \\
\hline Guan & 89.6 & 10.4 & & \\
\hline Mole-Dagbani & 88.3 & 11.7 & & \\
\hline Grusi & 88.5 & 11.5 & & \\
\hline Gurma & 89.8 & 10.2 & & \\
\hline Mande & 88.7 & 11.3 & & \\
\hline Other & 81.3 & 18.7 & & \\
\hline Parity & & & 14.6 & $0.002^{* *}$ \\
\hline 1 & 79.1 & 20.9 & & \\
\hline 2 & 84.9 & 15.1 & & \\
\hline 3 & 85.4 & 14.6 & & \\
\hline $4+$ & 86.1 & 13.9 & & \\
\hline ANC attendance & & & 5.7 & $0.037^{*}$ \\
\hline 0 & 85.7 & 14.3 & & \\
\hline $1-3$ & 91.0 & 9.0 & & \\
\hline $4+$ & 83.9 & 16.1 & & \\
\hline Type of delivery facility & & & 1.6 & 0.199 \\
\hline Public facility & 84.6 & 15.4 & & \\
\hline Private facility & 81.5 & 18.5 & & \\
\hline Sex of baby & & & 4.5 & $0.033^{*}$ \\
\hline Male & 82.8 & 17.2 & & \\
\hline Female & 85.8 & 14.2 & & \\
\hline Baby size & & & 6.0 & $0.039^{*}$ \\
\hline Small & 82.0 & 18.0 & & \\
\hline Average & 86.6 & 13.4 & & \\
\hline Large & 83.5 & 16.5 & & \\
\hline Household head sex & & & 10.3 & $0.001^{* *}$ \\
\hline Male & 85.5 & 14.5 & & \\
\hline Female & 80.0 & 20.0 & & \\
\hline
\end{tabular}

Source: Computed from 2014 GDHS

${ }^{*} p<0.05,{ }^{* *} p<0.01,{ }^{* * *} p<0.001$

weighted while the survey command (svy) in STATA was used to adjust for the complex sampling structure of the data in the regression analyses. 
Table 3 Multivariable logistic regression on factors associated with CD among women aged 15-49 years who gave birth in a health facility in Ghana

\begin{tabular}{|c|c|c|c|c|c|c|c|c|c|}
\hline Variable & $B$ & Wald & AOR (95\% Cl) & $P$-value & Variable & B & Wald & AOR (95\% Cl) & $P$-value \\
\hline Age & & & & & Guan & -.2168793 & -1.16 & $0.6(0.3-1.4)$ & 0.297 \\
\hline 15-19 & Ref & Ref & Ref & Ref & Mole-dagbani & .3332827 & 1.36 & $1.3(0.9-1.9)$ & 0.162 \\
\hline $20-24$ & .4572938 & 0.81 & $1.6(0.5-4.9)$ & 0.673 & Grusi & .027877 & 0.15 & $1.0(0.6-2.0)$ & 0.860 \\
\hline $25-29$ & 1.493462 & 2.22 & $3.5^{*}(1.2-10.5)$ & 0.015 & Gurma & -.0290065 & -0.15 & $0.9(0.5-1.9)$ & 0.887 \\
\hline $30-34$ & 1.584549 & 2.35 & $3.9 *(1.3-11.9)$ & 0.014 & Mande & .0144463 & 0.08 & $1.0(0.4-2.6)$ & 0.800 \\
\hline $35-39$ & 2.237171 & 3.47 & $7.5^{* * *}(2.4-23.6)$ & $<0.001$ & Other & .0903776 & 0.68 & $0.3(0.6-2.7)$ & 0.446 \\
\hline $40-44$ & 1.684761 & 3.44 & $7.9^{* * *}(2.4-25.9)$ & $<0.001$ & Parity & & & & \\
\hline $45-49$ & 1.088429 & 3.64 & $10.5^{* * *}(3.0-37.4)$ & $<0.001$ & 1 & Ref & Ref & Ref & Ref \\
\hline Education & & & & & 2 & -.693029 & -3.59 & $0.5^{* * *}(0.4-0.8)$ & $<0.001$ \\
\hline No education & Ref & Ref & Ref & Ref & 3 & -.9006956 & -4.45 & $0.4^{* * *}(0.3-0.6)$ & $<0.001$ \\
\hline Primary & -.0980253 & -0.44 & $0.9(0.5-1.5)$ & 0.674 & $4+$ & -1.505626 & -5.42 & $0.3^{* * *}(0.2-0.5)$ & $<0.001$ \\
\hline Secondary & .2760785 & 1.07 & $1.2(0.9-1.8)$ & 0.279 & ANC attendance & & & & \\
\hline Higher & .3377849 & 1.65 & $1.5(0.9-2.3)$ & 0.065 & 0 & Ref & Ref & Ref & Ref \\
\hline Occupation & & & & & $1-3$ & -.2792714 & -0.55 & $0.6(0.1-3.1)$ & 0.599 \\
\hline Not working & Ref & Ref & Ref & Ref & $4+$ & -.0799195 & -0.16 & $0.9(0.2-3.8)$ & 0.878 \\
\hline Primary & .0396569 & -0.15 & $1.0(0.6-1.5)$ & 0.781 & Sex of baby & & & & \\
\hline Secondary & .0127996 & 0.06 & $1.0(0.7-1.5)$ & 0.910 & Male & Ref & Ref & Ref & Ref \\
\hline Tertiary & -.0845761 & -0.37 & $0.9(0.7-1.3)$ & 0.654 & Female & -.3017619 & -1.99 & $0.8^{*}(0.6-0.9)$ & 0.041 \\
\hline Wealth status & & & & & Baby size & & & & \\
\hline Poorest & Ref & Ref & Ref & Ref & Small & Ref & Ref & Ref & Ref \\
\hline Poorer & -.2160541 & -0.9 & $0.8(0.5-1.3)$ & 0.406 & Average & -.3214023 & -1.9 & $0.8(0.6-1.0)$ & 0.055 \\
\hline Middle & -.0459008 & -0.17 & $1.0(0.6-1.5)$ & 0.897 & Large & .1791053 & 1.14 & $1.2(0.9-1.6)$ & 0.248 \\
\hline Richer & .0817143 & 0.28 & $1.1(0.6-1.8)$ & 0.594 & Sex of household & lead & & & \\
\hline Richest & .4890988 & 1.62 & 1.6(0.9-2.8) & 0.049 & Male & Ref & Ref & Ref & Ref \\
\hline Residence & & & & & Female & .2883202 & 1.97 & $1.3^{*}(1.1-1.7)$ & 0.027 \\
\hline Rural & Ref & Ref & Ref & Ref & $\mathrm{N}$ & & & 2742 & \\
\hline Urban & -.0085122 & -0.04 & $1.0(0.7-1.4)$ & 0.953 & Pseudo R-sq & & & 0.1 & \\
\hline
\end{tabular}

Region

$\begin{array}{lllll}\text { Western } & \text { Ref } & \text { Ref } & \text { Ref } & \text { Ref } \\ \text { Central } & .0428719 & 0.23 & 1.1(0.7-1.6) & 0.812 \\ \text { Greater Accra } & .0644161 & 0.33 & 1.1(0.7-1.7) & 0.780 \\ \text { Volta } & -.1135017 & -0.51 & 0.9(0.5-1.6) & 0.625 \\ \text { Eastern } & -.0720176 & -0.37 & 0.9(0.6-1.5) & 0.647 \\ \text { Ashanti } & .0036808 & 0.02 & 1.0(0.7-1.6) & 0.849 \\ \text { Brong Ahafo } & -.2788066 & -1.33 & 0.7(0.5-1.2) & 0.134 \\ \text { Northern } & -.4362156 & -1.81 & 0.6(0.3-1.0) & 0.074 \\ \text { Upper East } & -.8430196 & -2.89 & 0.4^{* *}(0.2-0.7) & 0.003 \\ \text { Upper West } & -.6549388 & -2.59 & 0.4^{* *}(0.2-0.8) & 0.008 \\ \text { Ethnicity } & & & & \\ \text { Akan } & \text { Ref } & \text { Ref } & \text { Ref } & \text { Ref } \\ \text { Ga/dangme } & -.0516319 & -0.35 & 0.9(0.6-1.5) & 0.625 \\ \text { Ewe } & -.2252556 & -1.2 & 0.8(0.5-1.2) & 0.310\end{array}$

Table 3 Multivariable logistic regression on factors associated with CD among women aged 15-49 years who gave birth in a health facility in Ghana (Continued)

Source: Computed from $2014 \mathrm{GDHS}$

${ }^{*} p<0.05,{ }^{* *} p<0.01,{ }^{* * *} p<0.001$, Ref Reference, AOR adjusted odds ratio, $\mathrm{Cl}$ confidence interval

\section{Results}

Maternal socio-demographic characteristics

The survey included the weighted total population of 2742 women who had given birth in health facilities 5 years preceding the survey. Regarding their age distribution, $25 \%$ of study participants were in the age range 25-29 years and 30-34 years respectively. For marital status, 7 out of 10 of the women were married. With education, $63 \%$ had a secondary level of formal education. Slightly more than half (51.6\%) were working in the tertiary sector while $16.2 \%$ were non-working mothers whereas $25.8 \%$ belonged to the richest quintile of wealth. As far as the region and place of residence were concerned, more than half of the mothers (56.2\%) resided in urban areas, while $20.4 \%$ were inhabitants of greater 
Accra region. Akans also constituted half (50.4\%) of the sample (see Table 1).

\section{Prevalence of caesarean delivery}

Figure 1 shows results on the prevalence of CD among child-bearing women in Ghana. Out of the 2742 women who had given birth in health facilities 5 years preceding the survey, $18.5 \%$ delivered their babies through CS and $81.5 \%$ had VD.

\section{Bivariate analysis on delivery by caesarean section}

From Table 2, it was shown that there were statistically significant differences in age $\left(\chi^{2}=37.5, p<0.001\right)$, education $\left(\chi^{2}=50.4, p<0.001\right)$, occupation $\left(\chi^{2}=23.6, p<0.001\right)$, wealth $\left(\chi^{2}=95.2, p<0.001\right)$, region $\left(\chi^{2}=65.2, p<0.001\right)$, residence $\left(x^{2}=31.4, \quad p<0.001\right)$, ethnicity $\left(x^{2}=32.1\right.$, $p<0.001)$, parity $\left(\chi^{2}=14.6, p<0.01\right)$, ANC attendance $\left(\chi^{2}=5.7, p<0.05\right)$, sex of baby $\left(\chi^{2}=4.5, p<0.05\right)$, baby size $\left(x^{2}=6.0, p<0.05\right)$, and sex of household head $\left(\chi^{2}=10.3\right.$, $p<0.01)$ and CD. The results further revealed that $21 \%$ of the respondents aged 35-39 and 45-49 delivered their children through CS. Approximately, a quarter $24.7 \%$ of the respondents with higher level of education delivered their children through CS, $28.5 \%$ of mothers who delivered through CS were in the richest domain, $25.1 \%$ were in greater Accra region. It was also found that $20.2 \%$ were Ga/Adagmes, $20.9 \%$ had parity $1,16.1 \%$ were those who had 4 or more ANC visits (see Table 2).

\section{Multivariable analysis}

Using multivariable logistic regression analysis, the data showed that women aged 45-49 had higher odds of giving birth by CS compared to women aged 15-19 years (AOR $=10.5$; 95\% CI: 3.0-37.4), and women from household that are headed by females $(\mathrm{AOR}=1.3 ; 95 \% \mathrm{CI}=$ 1.0-1.7) compared to women in households headed by males. Women from the Upper East $(\mathrm{AOR}=0.4 ; 95 \%$

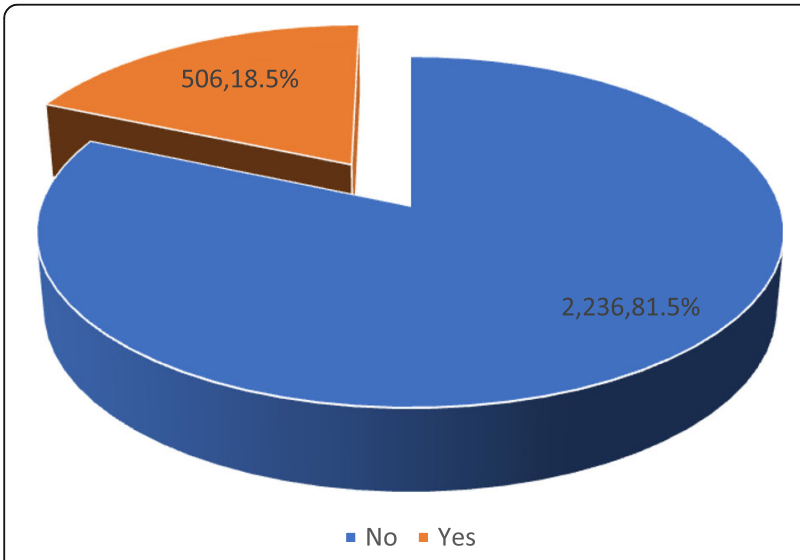

Fig. 1 Prevalence of caesarean delivery. Source: computed from 2014 GDHS
$\mathrm{CI}=0.2-0.7)$ and Upper West $(\mathrm{AOR}=0.4 ; 95 \% \mathrm{CI}=0.2-$ $0.8)$ regions were less likely to deliver children by CS compared to women from the Western region. Similarly, the odds of $\mathrm{CD}$ decreased with an increase in parity. For example, women with parity $3(\mathrm{AOR}=0.4 ; 95 \% \mathrm{CI}=$ $0.3-0.6), 4$ or more had about 0.3 lower odds of CD deliveries $(\mathrm{AOR}=0.3 ; 95 \% \mathrm{CI}=0.2-0.5)$ compared to those with parity 1 . Women with female babies had lower odds of $\mathrm{CD}$ (AOR $=0.8 ; \mathrm{CI}=0.7-0.9$ ) compared to those with male children (see Table 3).

\section{Discussion}

CS is a mechanism to save both the mother and the baby. However, delay in deciding for it may be detrimental for both. Nonetheless, premature and wrong decision opting for CD may increase maternal and foetal morbidity and mortality [31]. This paper sought to assess the factors associated with $\mathrm{CD}$ among childbearing women in Ghana. This present study found that $18.5 \%$ of women who delivered in health facilities 5 years preceding the survey delivered their babies through CS, a figure that exceeds the threshold of 5-15\% recommended by WHO [7]. This corroborates the findings in previous studies in low- and -middle income countries such as Pakistan [1], Egypt, [11], Bangladesh [12], Ethiopia [31], India [32], Jordan [33] and Tanzania [34]. An improved propensity toward available medical interventions and continued discouragement of VD after previous CS may have added to the recent increase in CS rates as noted in other countries [35]. Despite the fact that the study was not designed to measure the effect of changes in other maternal characteristics (e.g. Maternal requests), other determinants such as temporal changes in maternal prepregnancy weight, weight gain in pregnancy; and other characteristics may also have accounted for the observed increases in CD rates in Ghana. For example, the fear of childbirth, issues related to control and safety as well as risk associated with VD have been cited in previous studies as key reasons for CS [36]. However, the proportion is lower than what was found in Ghana by [14]. The possible reason for the inconsistency in study findings could be the study setting, the number of people that were used for the various studies and the years the studies were carried out as well as methodological designs. These findings imply that there should be encouragement of VD unless otherwise stated by a medical practitioner. Importantly, due to logistical constraints in most health facilities, especially in the rural areas of the country, it is equally prudent to raise clients' and health professionals' awareness about the adverse outcomes associated with $\mathrm{CD}$ and advantages of VD. Educating mothers about risks associated with $\mathrm{CD}$ and effective midwifery training could also help encourage mothers to deliver vaginally $[1]$. 
This study found a positive relationship between the odds of CD and age of mothers. Specifically, the odds of CD increased with their age. Those aged 45-49 had higher odds of CD compared to those aged 15-19. Findings of the current study, which involved data from a wider coverage of women across Ghana show evidence that advanced maternal age is a higher risk factor for CS and that the extent of the risk surges with advancement in maternal age, a finding that is corroborated in other studies [1, 11, 12, 28, 29, 37-39]. Berkowitz et al. [40] reiterated that advanced maternal age is generally believed to be associated with increased risk for adverse pregnancy outcome. Additionally, biological changes and complications (e.g., malposition, increased risk of hypertension, eclampsia, and diabetes) associated with aging pregnant women may heighten the risk of CD [41, 42]. Due to the increase in risk, some women voluntary opt for $\mathrm{CD}$ [43].

$\mathrm{CD}$ in this study was associated with the region of residence. Those in Upper East and Upper West regions had lower odds of CD compared to women in the Western Region. This finding is confirmed in other studies on the relationship between the geographical location and CD [1, 44]. Mothers staying in less developed regions are less likely to use CD services compared to those in regions that are more developed. The reason could be the easy access, availability and utilization of maternal healthcare facilities at private and public hospitals in the southern part of Ghana compared to the limited healthcare facilities in the Northern part of Ghana [14]. Additionally, there is better access to $C D$ due to the high numbers of health facilities with the capacity to conduct CD in the souther part of Ghana [30].

There was an inverse relationship between parity and the odds of CD. Those with about 4 or more births had lower odds of delivering their babies through CS. This finding is consistent with previous research [13-15]. As explained by Manyeh et al. [14] on CD, women who might have undergone more than $1 \mathrm{CD}$ do not get pregnant again to avoid further CD. Additionally, once the woman's pelvis has been tested with a previous pregnancy and VD, subsequent deliveries vaginally tend to be less risky [15]. Hence, mothers who have had a lot of experiences with VD may be less likely to go in for CD.

Another significant finding in this current study was that mothers with female babies had lower odds of CD compared to those who had male children. From a socio-cultural perspective, the uncertainty attached to CD by most women of sub-Saharan descent due to its associated unpleasant experiences (e.g., physical, psychological and emotional pain/distress) suggest that the mothers with female babies may wish not to have CD because of a commonly held belief that such painful CD experiences might be transferred to their daughters later in life. Related to this households with a female as the head were more likely to go for CD compared to those headed by males, a finding similar to a Ghanaian community-based study [14]. What is unclear is whether this particular finding could be associated with the diverse sociocultural differences emanating from varied ethnic background of the women groups used for the study. It is therefore imperative for further studies to consider the association between the sex household head and $\mathrm{CD}$ to unearth the nuances.

\section{Strength and limitations of the study}

By investigating caesarean outcomes of women from different cohort groups, this study realizes the arduous responsibility of discovering CD trends overtime among these diverse women groups. However, this study is not without limitations. First, the data did not capture any specific type of pregnancy complication that resulted in CD which could not help to ascertain whether performed $C D$ was under medical indications (e.g., fetal mal-presentation) or based solely on maternal demand. Also, due to the cross-sectional nature of the study, causality could not be expressed between any of the independent variables and CD. Other limitations may include those commonly related to large database research such as alterations in the coding of procedures in charts, tables and other data abstraction errors. However, no considerable modifications were done during coding and extraction in the conduct of this study. Despite these limitations, this study provides evidence-based estimates on the prevalence of $\mathrm{CD}$ among women giving birth in health facilities in Ghana, as well as its associated factors.

\section{Conclusion and policy implications}

In conclusion, women route of delivery is a potentially modifiable risk factor that are at two ends of the child delivery continuum (i.e., caesarean versus vaginal). The foregoing investigation of $\mathrm{CD}$ rates and associated factors as well as geographical differences would provide vital data for obstetric decision making on this medical intervention. The study findings show that the current CD in Ghana is approximately $18.5 \%$ which is above the WHO recommended proportion of $5-15 \%$. The study also revealed strong associations between maternal age, region, parity, baby's sex, and sex of household head and the probability of $\mathrm{CD}$. Specifically, female babies are less likely to be delivered via CS whereas women with female househild head are more likely to deliver through CS. The high rates of $C D$ noted in the current study do not essentially indicate good quality care or services. Health institutions with high CS rate should conduct comprehensive assessment of the associated factors toward obstetric care. Detailed medical justification for performing 
CS by doctors should also be provided to reduce the proportions of women opting for $\mathrm{CD}$. Additionally, other quantitative and qualitative research ought to be conducted to better understand the socio-cultural beliefs, psychological factors and perceptions of Ghanaian women that may be contributing to the high uptake of CD in Ghana.

\section{Abbreviations \\ ANC: Antenatal Care; AOR: Adjusted Odds Ratio; CD: Caesarean Delivery; Cl: Confidence Interval; CS: Caesarean Section; GDHS: Ghana Demographic and Health Surveys; MMR: Maternal Mortality Ratio; WHO: World Health Organization}

\section{Acknowledgements}

We acknowledge Measure DHS for providing us with the data.

\section{Authors' contributions}

AS conceived the study. AS designed and performed the analysis and write up on data and methods. AS, BOA, and WA designed the first draft of the manuscript. AS, JEH, BOA, WA, EBN, EB, FS, and TS revised the manuscript for intellectual content and gave consent for the version to be published. All authors read and approved the final manuscript.

\section{Funding}

This research did not receive any specific grant from funding agencies in the public, commercial, or not-for-profit sectors.

\section{Availability of data and materials}

Data is available on https://dhsprogram.com/what-we-do/survey/surveydisplay-437.cfm.

\section{Ethics approval and consent to participate}

The DHS was approved by the institutional review board of the Ghana Health Service and the ethics committee of the DHS Program. Informed consent, both written and oral were obtained from the respondents before the commencement of interviews with each respondent.

\section{Consent for publication}

Not applicable.

\section{Competing interests}

The authors declare that they have no competing interests.

\section{Author details}

'Department of Population and Health, University of Cape Coast, Cape Coast, Ghana. ${ }^{2}$ Department of Health, Physical Education and Recreation, University of Cape Coast, Cape Coast, Ghana. ${ }^{3}$ Neurocognition and

Action-Biomechanics Research Group, Faculty of Psychology and Sport Sciences, Bielefeld University, Bielefeld, Germany. ${ }^{4}$ The Australian Centre for Public and Population Health Research (ACPPHR), Faculty of Health, University of Technology Sydney, Ultimo, Australia. ${ }^{5}$ Ghana Health Service, Abura Dunkwa Health Directorate, Abura Dunkwa, Ghana.

Received: 16 November 2019 Accepted: 5 February 2020 Published online: 18 February 2020

\section{References}

1. Amjad A, Amjad U, Zakar R, Usman A, Zakar MZ, Fischer F. Factors associated with caesarean deliveries among child-bearing women in Pakistan: secondary analysis of data from the demographic and health survey, 2012-13. BMC Pregnancy Childbirth. 2018;18(1):113.

2. Asuquo EO, Orazulike NC, Onyekwere EC, Odjegba JN, Ojo Al, Ogbansiegbe JA. Factors associated with preference for caesarean section among women in the ante-natal clinic of a tertiary hospital in the Niger Delta, Nigeria. A pilot study. J Adv Med Med Res. 2016:29:1-9.

3. Betran AP, Ye J, Moller AB, Zhang J, Gülmezoglu AM, Torloni MR. The increasing trend in caesarean section rates: global, regional and nationa estimates: 1990-2014. PLoS One. 2016;11(2):e0148343.
4. Harrison MS, Goldenberg RL. Cesarean section in sub-Saharan Africa. Matern Health Neonatol Perinatol. 2016:2(1):6.

5. Souza JP, Gülmezoglu A, Lumbiganon P, Laopaiboon M, Carroli G, Fawole B, Ruyan P, WHO Global Survey on Maternal and Perinatal Health Research Group. Caesarean section without medical indications is associated with an increased risk of adverse short-term maternal outcomes: the 2004-2008 WHO Global Survey on Maternal and Perinatal Health. BMC Med. 2010;8(1):71.

6. Babill S-P. Lecture note "assisted delivery". Oslo: Rikshospitalet, University Hospital; 2012.

7. World Health Organization. Provision of effective antenatal care: integrated management of pregnancy and childbirth. Geneva: World Health Organization; 2016.

8. Ostovar R, Rashidian A, Pourreza A, Rashidi BH, Hantooshzadeh S, Ardebili HE, Mahmoudi M. Developing criteria for cesarean section using the RAND appropriateness method. BMC pregnancy and childbirth. 2010:10(1):1-8.

9. Mekonen Y. Maternal health in Ethiopia: challenges in achieving the MDG for maternal mortality: in-depth analysis of the EDHS 2000-2011. Addis Ababa: UNFPA; 2012

10. Kahsay S, Berhe G, Gebremari A. Determinants of caesarean deliveries and its major indications in Adigrat hospital, Northern Ethiopia: a case-control study. Epidemiology. 2015;5:3-5.

11. Al Rifai RH. The trend of caesarean deliveries in Egypt and its associated factors: evidence from national surveys, 2005-2014. BMC Pregnancy Childbirth. 2017;17(1):417-25.

12. Begum T, Rahman A, Nababan H, Hoque DM, Khan AF, Ali T, Anwar I. Indications and determinants of caesarean section delivery: evidence from a population-based study in Matlab, Bangladesh. PloS One. 2017;12(11):e0188074.

13. Janoudi G, Kelly S, Yasseen A, Hamam H, Moretti F, Walker M. Factors associated with increased rates of caesarean section in women of advanced maternal age. J Obstet Gynaecol Can. 2015:37(6):517-26.

14. Manyeh AK, Amu A, Akpakli DE, Williams J, Gyapong M. Socioeconomic and demographic factors associated with caesarean section delivery in Southern Ghana: evidence from INDEPTH network member site. BMC Pregnancy Childbirth. 2018:18(1):405.

15. Mgaya AH, Massawe SN, Kidanto HL, Mgaya HN. Grand multiparity: is it still a risk in pregnancy? BMC Pregnancy Childbirth. 2013;13(1):241.

16. Stanton CK, Holtz SA. Levels and trends in cesarean birth in the developing world. Stud Fam Plan. 2006;37(1):41-8

17. Huang K, Tao F, Faragher B, Raven J, Tolhurst R, Tang S, Van Den Broek N. A mixed-method study of factors associated with differences in caesarean section rates at community level: the case of rural China. Midwifery. 2013; 29(8):911-20.

18. Stanton C, Castro A, Adanu R, Heymann M, Adu-Bonsaffoh K, Lattof SR, Blanc A, Langer A. Measuring coverage in MNCH: validating women's selfreport of emergency cesarean sections in Ghana and the Dominican Republic. PLoS One. 2013;8(5):e60761

19. World Health Organization. World health statistics. http://www.who.int/ whosis/whostat/EN_WHS10_Full.pdf. 2010

20. Teguete I, Dolo A, Sissoko A, Thera A, Traore M, Dire MY, Mounkoro N, Dolo $T$, Traore $Y$. Determining factors of cesarean delivery trends in developing countries: lessons from point G National Hospital (Bamako-Mali). INTECH Open Access. 2012 May 23:161-202. Available from http://www.intechopen. $\mathrm{com} /$ books/cesarean-delivery/determining-factors-of-cesareandeliverytrends-in-developing-countries-lessons-from-point-g-nat.

21. Danso KA, Schwandt HM, Turpin CA, Seffah JD, Samba A, Hindin MJ. Preference of Ghanaian women for vaginal or caesarean delivery postpartum. Ghana Med J. 2009:43(1):29.

22. Seffah JD, Adu-Bonsaffoh K. Vaginal birth after a previous caesarean section: current trends and outlook in Ghana. J West Afr Coll Surg. 2014:4(2):1.

23. Prah J, Kudom A, Afrifa A, Abdulai M, Sirikyi I, Abu E. Caesarean section in a primary health facility in Ghana: clinical indications and feto-maternal outcomes. J Public Health Afr. 2017:8(2):704.

24. Ghana Statistical Service (GSS), Ghana Health Service (GHS), ICF International. Ghana demographic and health survey 2014. Rockville: GSS, GHS, ICF International; 2015.

25. Apanga PA, Awoonor-Williams JK. Predictors of caesarean section in northern Ghana: a case-control study. Pan Afr Med J. 2018;29(1):1-1.

26. Ghana Statistical Service (GSS). Ghana demographic and health survey, 2008 2010.

27. Bayrampour $\mathrm{H}$, Heaman M. Advanced maternal age and the risk of cesarean birth: a systematic review. Birth. 2010;37(3):219-26. 
28. Ghana Health Service. Annual report. Accra: Ghana Health Service; 2011. p. 2011.

29. Rebelo F, Da Rocha CM, Cortes TR, Dutra CL, Kac G. High cesarean prevalence in a national population-based study in Brazil: the role of private practice. Acta Obstet Gynecol Scand. 2010;89(7):903-8.

30. Ghana Health Service. Family health division annual report. Accra: Ghana Health Service; 2016.

31. Abebe FE, Gebeyehu AW, Kidane AN, Eyassu GA. Factors leading to cesarean section delivery at Felegehiwot referral hospital, Northwest Ethiopia: a retrospective record review. Reprod Health. 2015;13(1):6.

32. Singh P, Hashmi G, Swain PK. High prevalence of cesarean section births in private sector health facilities-analysis of district level household survey-4 (DLHS-4) of India. BMC Public Health. 2018;18(1):613.

33. Abu Anza SH, Abu Omar AA. Frequency rate and indications of cesarean sections at Prince Zaid bin Al Hussein Hospital-Jordan. J R Med Serv. 2012; 102(354):1-5.

34. Dekker L, Houtzager T, Kilume O, Horogo J, van Roosmalen J, Nyamtema AS. Caesarean section audit to improve quality of care in a rural referral hospital in Tanzania. BMC Pregnancy Childbirth. 2018;18(1):164.

35. Menacker F, Declercq E, Macdorman MF. Cesarean delivery: background trends, and epidemiology. Semin Perinatol. 2006;30(5):235-41 WB Saunders.

36. Fenwick J, Staff L, Gamble J, Creedy DK, Bayes S. Why do women request caesarean section in a normal, healthy first pregnancy? Midwifery. 2010; 26(4):394-400.

37. Carolan M, Davey MA, Biro MA, Kealy M. Older maternal age and intervention in labour: a population-based study comparing older and younger first-time mothers in Victoria, Australia. Birth. 2011;38(1):24-9.

38. Hanif HM. Association between maternal age and pregnancy outcome: implications for the Pakistani society. J Pak Med Assoc. 2011;61:313-9.

39. Lin HC, Sheen TC, Tang CH, Kao S. Association between maternal age and the likelihood of a cesarean section: a population-based multivariate logistic regression analysis. Acta Obstet Gynecol Scand. 2004;83(12):1178-83.

40. Berkowitz GS, Skovron ML, Lapinski RH, Berkowitz RL. Delayed childbearing and the outcome of pregnancy. N Engl J Med. 1990;322(10):659-64.

41. Luke B, Brown MB. Elevated risks of pregnancy complications and adverse outcomes with increasing maternal age. Hum Reprod. 2007;22(5):1264-72.

42. Zgheib SM, Kacim M, Kostev K. Prevalence of and risk factors associated with cesarean section in Lebanon-a retrospective study based on a sample of 29,270 women. Women Birth. 2017;30(6):e265-71.

43. Ecker JL, Chen KT, Cohen AP, Riley LE, Lieberman ES. Increased risk of cesarean delivery with advancing maternal age: indications and associated factors in nulliparous women. Am J Obstet Gynecol. 2001;185(4):883-7.

44. Nazir S. Determinants of cesarean deliveries in Pakistan. Islamabad: Pakistan Institute of Development Economics; 2015.

\section{Publisher's Note}

Springer Nature remains neutral with regard to jurisdictional claims in published maps and institutional affiliations.

Ready to submit your research? Choose BMC and benefit from:

- fast, convenient online submission

- thorough peer review by experienced researchers in your field

- rapid publication on acceptance

- support for research data, including large and complex data types

- gold Open Access which fosters wider collaboration and increased citations

- maximum visibility for your research: over $100 \mathrm{M}$ website views per year

At BMC, research is always in progress.

Learn more biomedcentral.com/submissions 